\title{
Infrastructure and Flight Consolidation Efficiency of Public and Private Brazilian International Airports: A Two-Stage DEA and Malmquist Index Approach
}

\author{
Antonio Carlos Pacagnella Junior (D), Paulo Sodre Hollaender (D), \\ Giovanni Vitale Mazzanati, and Wagner Wilson Bortoletto
}

School of Applied Sciences-FCA, State University of Campinas-UNICAMP, Campinas, Brazil
Correspondence should be addressed to Antonio Carlos Pacagnella Junior; acpjr@unicamp.br

Received 12 September 2019; Revised 1 July 2020; Accepted 20 July 2020; Published 28 August 2020

Academic Editor: Rocío de Oña

Copyright ( 2020 Antonio Carlos Pacagnella Junior et al. This is an open access article distributed under the Creative Commons Attribution License, which permits unrestricted use, distribution, and reproduction in any medium, provided the original work is properly cited.

\begin{abstract}
Air transportation is a paramount element within the transport infrastructure of any country. In recent years, several factors have led to an increased demand in the civil aviation industry in Brazil, putting pressure on the country's airport infrastructure, which by itself justifies industry-related efficiency studies. Although the airport efficiency analysis is widely discussed in the literature, studies aiming to compare public and private Brazilian international airports are still scarce. The main objective of this study is to comparatively analyze the efficiency of public and private Brazilian international airports. To do so, efficiency was studied under two mathematical approaches: the two-stage DEA model and the Malmquist Index. Subsequent statistical analyses show a significant difference in efficiency between government-managed airports and those under concession to the private sector.
\end{abstract}

\section{Introduction}

Air transportation is an important element within the transport infrastructure of any country, as it expands the integration among distant regions and enables national and international consumer and supply relations for high valueadded or high obsolescence items.

To fully understand its relevance to the economy, air transport is responsible for the transit of about 2 billion people and for about $40 \%$ of the exports and imports of products (in value) per year worldwide [1].

Given this context, airports are regarded as important instruments to economically and technically enable the air transport of cargo and people nationally or internationally. Their infrastructure allows the receipt, storage, and dispatch of goods to correct destinations, in addition to passenger service and processing.

Chao and $\mathrm{Yu}$ [2] state that airports are also seen as portals between countries, playing a fundamental role in both passenger flow and international business. In addition, the sector has recently experienced a strong growth throughout the world, and an average growth rate of 5.8\% per year is expected from 2009 to 2028 [3].

Air transport was popularized due to the recent economic growth in Brazil, thus including social classes that previously did not consider such transport system. This led to an increased demand for domestic airports.

According to Assaf et al. [4], the rapid growth in air traffic, in addition to the lack of government resources, has been causing the need for airports to raise capital for expansion from other sources, demanding a reassessment on the near exclusivity of government management.

Following this line, the Brazilian government recently started a management privatization process with the airports of Guarulhos (GRU), Brasília (BRB), Campinas (VCP), Confins (CNF), Galeão (GIG), and São Gonçalo do Amarante (NAT), seeking to obtain investments for improving their infrastructure and, consequently, their operations. 
Thenceforth, the Brazilian air transport sector introduced changes that draw the attention of the whole society, posing a challenge to public managers and area researchers. The importance of the sector for the country's development and the increased demand implies the need for an efficient airport management, seeking balance to ensure the quality of the services offered.

Although this topic is widely discussed in the literature, studies on the management of airport operations frequently focus on very specific aspects. According to Weiszer et al. [5], most research studies conducted on this topic focus on aspects such as optimization; flight scheduling; minimizing delays, taxiing time, or even the aircraft fuel consumption; and the handling of cargo, hardly addressing the management of their operations as a whole.

Over the last years, however, a broader approach has been widely used in the study of airport operations-the efficiency study. When observing the literature available on the subject, the studies of Wanke [6], Merkert and Mangia [7], and Chung et al. [8] can be highlighted.

The proliferation of empirical studies assessing the efficiency at the level of airport infrastructures is such that, today, it is one of the key research issues within airport economics and management [9].

Studies on airport efficiency allow the construction of a ranking to point out those that can be a benchmark to other airports, provided that their operations are mapped and analyzed in comparison with inefficient airports.

Though the efficiency analysis in airports is widely discussed in the literature, this is not true for studies aiming to compare public and private airports, which are scarce $[10,11,12]$. Besides, according to Lo Storto [13], recently, there has been a growing interest of scholars and policymakers in the measurement of airport performance, in particular, to evaluate the potential benefits of private sector involvement and, more generally, to evaluate productivity and operational efficiency.

By analyzing the scientific literature (as shown in Section 2 ), it is possible to verify that there is no consensus about the influence of the form of ownership/management on the performance of the airports, so this issue still presents a gap to be fulfilled. In particular, in Brazil, just a few research studies were made and we hope to contribute to improve the understanding of this theme.

Studies of this kind can contribute in two different ways: firstly, in business, providing subsidies to evaluate the effectiveness of privatization policies, and secondly academically, by seeking to broaden the grasp of a phenomenon not yet fully understood by the scientific literature of the area. Therefore, considering the arguments presented, this article aims to analyze the efficiency of public and private Brazilian airports in a comparative way.

To achieve such goal, this study is structured into five sections. In Section 2, after this brief introduction, considerations on the methodological aspects of the study are presented. Section 3 presents the theoretical reference, including the mathematical bases of the approaches used in the research. The results found are discussed in Section 4 . Section 5 produces the conclusions obtained and the final considerations of the study.

\section{Literature Review}

According to Carlucci et al. [14], airport privatization, globalization, and increased competition have generated business pressures on operating firms. This has wakened interest in performance benchmarking and pushed airports to place more emphasis on quality.

According to Ferreira et al. [15], the search for the best form of airport management or ownership is a worldwide phenomenon and the reason for this is related to the fact that airports are not limited to serve just as a support structure for the aeronautical industry, but it also the basis for an entire business with huge involvement and tremendous regional economic growth.

A number of studies investigated the impact of different forms of ownership, particularly privatization, on airport efficiency; however, as Liebert and Niemeier [16] emphasize, results from several empirical studies that analyzed the relationship between ownership characteristic and the efficiency of airports are often ambiguous and inconsistent. Some of these studies provided evidences of the influence of the ownership form on airport efficiency (some of them shows that this relationship depends on factors such as competitive environment, the concession agreement, governance structure, and economies of scale generated by characteristics of the airport) while others were unable to indicate any relevant effect.

Among the studies that show results supporting the hypothesis that airport efficiency is related to the type of property, it is possible to highlight the studies of Oum et al. [11], Malighetti et al. [17], Assaf et al. [4], Gitto and Mancuso [18], Perelman and Serebrisky [19], Adler et al. [20], and Chen and Lai [21]. In all these research studies, the general idea, based on empirical results, is that private ownership airports are more efficient than public ones.

Oum et al. [11] studied a sample of North American and European airports during 2001-2003 to evaluate productive efficiency and profitability and found that airports with government majority ownership are less efficient than airports with private majority ownership. Malighetti et al. [17] studied the technical efficiency of Italian airports applying a DEA model to 34 airports over the period 2005-2006 and their results showed a positive effect of private ownership on airport efficiency. Assaf et al. [4] measured efficiency in major Australian airports in the period of 2002 to 2007 using a bootstrapped DEA. His results showed that most airports had a significant efficiency improvement after the privatization process. Gitto and Mancuso [18] used two DEA models to evaluate the impact of the regulation form on the efficiency of a sample of 28 airports in Italy. They found that the inflow of private capital and the type of concession have a positive impact on airport efficiency. Perelman and Serebrisky [19] studied a sample of 20 airports in Latin America from 2000 to 2007 and found that the growth rate of productivity of private airports was bigger than that of public airports within this period. Adler et al. [20] analyzed a sample of 48 European and 3 Australian airports using a DEA model and regression analysis. Their results showed that public airports operate less cost-efficiently than fully 
private airports. Chen and Lai [21] adopted a dynamic stochastic production frontier approach to estimate the individual production adjustment speed and their short-run and long-run technical efficiencies. The results show that private airports have a faster production adjustment.

However, other studies showed exactly the opposite that publicly owned or managed airports are more efficient than private airports, such as studies of Oum et al. [22], Curi et al. [23], Martini et al. [24], Gutiérrez and Lozano [25], and Parashi et al. [26].

Oum et al. [22] studied the technical efficiency applying stochastic frontier analysis to a panel data of the world's major airports, and their results suggest that a mixed ownership structure with a government majority should be avoided preferring, instead of a $100 \%$ government-owned public firm. Curi et al [23] analyzed the impacts of Italian government actions on the efficiency of 36 airports between 2002 and 2003 using a two-stage data envelopment analysis with bootstrapping. Martini et al [24] analyzed the efficiency of 33 Italian airports for the period 2005-2008 with a directional distance function (DDF) model and get airports' efficiency scores and bootstrapping. Their results provided evidence that public airports have higher efficiency scores. Gutiérrez and Lozano [25] investigated the operational efficiency and potential output increase scenarios of 21 smalland medium-sized airports (SMAs) located in 10 different European countries using a DEA model and a fractional regression model. Among the results, it was found that the public owned airports tend to have a higher efficiency score. Paraschi et al. [26] used the Airport Business Excellence Model and a multiple regression analysis in a sample of 137 airports spread over 90 countries. Their results showed that blending public and private airport ownership has negative effects on efficiency.

A third group of studies did not find any difference between private or publicly owned/managed airports, such as Parker [27], Oum et al. [28]; Lin and Hong [29], Gitto and Mancuso [18], and Paraschi et al. [26].

Parker [27] used a DEA model to evaluate the effect of privatization of the former British Airports Authority in the technical efficiency of its airports. His results showed that privatization had no noticeable effect on performance across the different airports operated by the company over time. Oum et al. (2003) compared the efficiency of 50 major airports in Asia Pacific, Europe, and North America using regression analysis and found that airport's ownership structure does not appear to have any statistically significant effect on its performance. Lin and Hong [29] used data envelopment analysis to assess the operational performance of 20 major airports around the world. It is found that the form of ownership of an airport is not apparently correlated with the operational performance of airports. Gitto and Mancuso [18] also used a DEA model to assess the operational performance of 28 Italian airports during the period of 2000 through 2006. The results showed that the form of ownership (public majority vs. private majority) of an airport management company does not significantly affect performance. Ahn and Min [30] evaluated the comparative efficiencies of international airports for a multiyear period
(2006-2011) using data envelopment analysis intended for dynamic benchmarking and Malmquist productivity index. Their results indicate that the efficiency of an airport was influenced by exogenous factors such as shifts in government policies and technological advances rather than endogenous factors driven by improvements in managerial practices.

It is important to highlight that researchers have used different sizes of samples, number of variables, time periods, and of course, research methods. So, discrepancies across results are most likely due to differences in the research approach.

Considering the literature review presented in this section, it is possible to confirm that private versus public ownership/management and its relationship with airport efficiency remain a controversial issue as there is no strong evidence that involving the private sector is a guarantee (or at least an odds improvement) that there will be efficiency gains. Thus, the type of ownership/management and airport efficiency relationship still presents a gap that needs to be better investigated.

\section{Materials and Methods}

This section introduces the methodological aspects of the research. The proposal is conducting a quantitative efficiency analysis of 33 public and private Brazilian international airports by using a two-stage data envelopment analysis (DEA) model and by calculating the Malmquist Index. Results obtained through these techniques will also be statistically analyzed as shown below.

Studies were performed from secondary data collected by the Airports Council International (ACI). Data were extracted from three databases acquired for efficiency studies, namely, ACI Airport Key Performance Indicators, ACI Airport Economics Report, and ACI ANNUAL World Airport Traffic Report.

Data of the 33 Brazilian international airports, related to 2014 and 2015, were extracted from these databases. Among the airports analyzed, 28 were managed by the Brazilian government through the INFRAERO and 5 were administered by the private sector, under concession regimes. From these data, the efficiency of each airport was calculated in accordance with specific procedures for each approach, as described in the section on Theoretical Framework, presented below.

Efficiency values were submitted to descriptive and inferential statistical analyses to enable the comparative analysis of the efficiency of the airports included in this study. Parametric and nonparametric statistical procedures were performed according to the best adequacy of the datasets under scrutiny.

3.1. Data Envelopment Analysis (DEA). The technique was initially proposed by Charnes et al. [31], under the assumption of constant returns in the scale in the relationship between inputs and outputs, and was deepened by Banker et al. [32], who included a relation of variable scale returns 
between inputs and outputs. Ever since, new proposals for frontier estimation were created, such as cross-efficiency, radial efficiency, and superefficiency.

DEA is a nonparametric technique, which allows the efficiency evaluation of a set of observations (called decisionmaking units (DMUs)) considering the number of inputs consumed and the amount of outputs generated. According to Barros and Athanassiou [33], DEA models were developed to assess efficiency in two different ways. Input-oriented models are based on the minimization of inputs, assuming the same level of outputs, whereas output-oriented models are based on the maximization of outputs by assuming the same level of inputs.

The use of DEA models to calculate efficiency in airports is very common in the literature, as can be observed in Gillen and Lall [34], Fernandes and Pacheco [35], and D'alfonso et al. [36]. However, according to Lo Storto [37], the airport operational efficiency is critically affected by the interaction of several activities and processes. Thus, a traditional DEA approach can be not useful, and a network-DEA approach provides a more accurate measurement of efficiencies and indications for management.

Network-DEA approaches take into consideration the internal structure of the DMUs instead of considering them as black boxes like conventional DEA models, which considers a single process that consumes all the inputs and generates all the outputs. Network-DEA considers the existence of several stages that consumes its own set of inputs and produces its own set of outputs and intermediate products. These intermediate products are considered as inputs for some stages and outputs for others [38].

According to $\mathrm{Yu}$ [39], the airport production process can be divided into two stages, considering elements such as airport structure (terminal area, number of highways, and number of aprons) and also the airport service (aircraft takeoffs and landings) which can provide a more insightful vision of its efficiency.

In this sense, this study will adopt the network-DEA model proposed by Wanke [6], who also conducted a research on airports, reaching consistent results. His approach considers an output-oriented two-stage model, in which the first stage assesses the airport infrastructure efficiency and the second deals with the efficiency of cargo and passenger consolidation, as shown in Figure 1.

In the first stage, which is related to physical infrastructure, the area of the terminal, the number of slots for aircraft, and the number of runaways are inputs, whereas the number of landings and takeoffs are the outputs. This is to minimize the physical infrastructure required to achieve a given number of annual movements per year. As for the second stage, concerning the consolidation of landings and takeoffs per year, the number of landings and takeoffs are inputs and the amount of passengers and cargo traffic are the outputs and are used to determine the number of passengers per year, as well as a cargo throughput.

According to Wanke [6], one assumes, by using the twostage DEA model presented in Figure 1, that the airports are the decision-making units (DMUs) and that $\operatorname{DMU}_{j}(j=1$,
$2, \ldots, n)$ has $D$ intermediate measures $z d_{j}(d=1,2, \ldots, D)$, in addition to the initial inputs $x_{i j}(i=1,2, \ldots, m)$ and the final outputs $y_{r j}(r=1,2, \ldots, s)$. Furthermore, the weights $v_{i}, w_{d}$, and $r_{d}$ are considered, which are nonnegative and unknown. Thus, the two-stage DEA model has the following configuration:

$$
\begin{gathered}
\theta_{0}^{\text {global }}=\operatorname{Max} \sum_{r=1}^{s} u_{r} y_{r o}, \\
\sum_{r=1}^{s} u_{r} y_{r j}-\sum_{d=1}^{D} w_{d} z_{d j} \leq 0, \quad j=1,2, \ldots, n, \\
\sum_{d=1}^{D} w_{d} z_{d j}-\sum_{d=1}^{m} v_{1} x_{i j} \leq 0, \quad j=1,2, \ldots, n, \\
\sum_{i=1}^{m} v_{i} x_{i o}=1, \\
w_{d} \geq 0, d=1,2, \ldots, D, \\
v_{i} \geq 0, i=1,2, \ldots, m, \\
u_{r} \geq 0, r=1,2, \ldots, s,
\end{gathered}
$$

where $\theta_{0}^{\text {global }}$ is the level of global efficiency of the two-stage process for the $\mathrm{DMU}_{o}$. Presuming that model 1 has a single solution, the efficiencies for the first and second stages are calculated by the following equation:

$$
\begin{aligned}
& \theta_{0}^{\text {physical infrastructure }}=\sum_{d=1}^{D} w_{d} z_{d o}, \\
& \theta_{0}^{\text {flight consolidation }}=\frac{\sum_{r=1}^{S} u_{r}^{*} y_{r o}}{\sum_{d=1}^{D} w_{d}^{*} z_{d o}}
\end{aligned}
$$
define

Since a single solution is considered, it is possible to

$$
\theta_{0}^{\text {global }}=\theta_{0}^{\text {physical infrastructure }} * \theta_{0}^{\text {flight consolidation }} .
$$

Thus, the global efficiency of airports may be calculated as the product of two efficiencies, namely, physical structure efficiency, which is related to the use of infrastructure and its landing and takeoff capacity, and flight consolidation infrastructure, associated with the cargo and passenger processing from landings and takeoffs there performed.

A relevant issue is addressed by Cooper et al. [40], regarding the relationship between the number of decisionmaking units (DMUs) and inputs/outputs. The number of DMUs should be at least three times the number of inputs and outputs. Also, Wang et al. [41] state that inputs and outputs must have a positive correlation. Such parameters were respected in this study. 


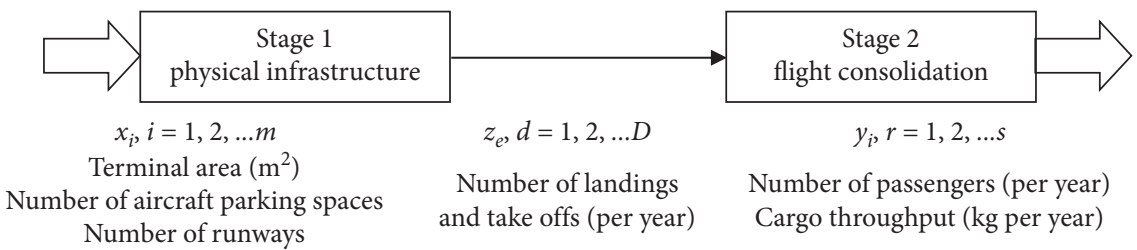

FIGURE 1: Stages of the estimation of efficiency in airports (source: adapted from Wanke [6]).

It is important to highlight that the model itself was already used with success before in Wanke [6]. Also, the model was presented to two airport operation directors and the evaluation regarding the feasibility and representativity of the model was positive. Besides, the addition of other variables as inputs or outputs in the model was not possible because of limitations in the ACI database.

3.2. Malmquist Index (MI). For analyzing a DMU performance over different periods of time, just numerically comparing the absolute numbers is unreasonable. That is because the efficiency presented by the DEA for each DMU occurs in relation to all the others, and, in two different moments of time, it is likely that the values of the inputs and outputs indicators will change for all units.

Thus, some tools that enable the comparison between these units in different moments are required. In the literature, the most consolidated tool is the Malmquist Index (MI). Such index was initially developed by Caves et al. [42] and, as stated by them, enables comparisons under very broad circumstances, provided that the data have inputs, outputs, and compatibility, in addition to adapting to arbitrary scale returns. One can therefore use the MI to compare a single DMU at different times.

In the case of a DEA with variable scale return, such as the DEA BCC, the approach to the Malmquist Index used in this article is that of Ray and Desli [43]. In it, the MI production function is given by the distance between the decision-making unit and the efficiency frontier, whereas the inputs remain constant.

The Malmquist Index consists of two factors: the technological change index (TC) and the technical efficiency change index, also known as catching up. This latter index may be divided into two terms: the pure efficiency change (PEC) and the scale change (SEC) indexes. Each of these indexes can be described by their respective equation, exemplified in a model with only one input and one output:

$$
\begin{aligned}
\mathrm{TC} & =\sqrt{\frac{D_{0}\left(x_{0}, y_{0}\right)}{D_{1}\left(x_{0}, y_{0}\right)} \cdot \frac{D_{0}\left(x_{1}, y_{1}\right)}{D_{1}\left(x_{1}, y_{1}\right)}}, \\
\mathrm{PEC} & =\frac{D_{1}\left(x_{1}, y_{1}\right)}{D_{0}\left(x_{0}, y_{0}\right)},
\end{aligned}
$$

$$
\mathrm{SEC}=\sqrt{\left[\frac{D_{0}\left(x_{1}, y_{1}\right)}{D_{0_{c}}\left(x_{1}, y_{1}\right)} \div \frac{D_{0}\left(x_{0}, y_{0}\right)}{D_{0_{c}}\left(x_{0}, y_{0}\right)}\right]\left[\frac{D_{1}\left(x_{1}, y_{1}\right)}{D_{1_{c}}\left(x_{1}, y_{1}\right)} \div \frac{D_{1}\left(x_{0}, y_{0}\right)}{D_{1_{c}}\left(x_{0}, y_{0}\right)}\right]} .
$$

Finally, the Malmquist Index is represented by the product of the three terms:

$$
\mathrm{MI}=\mathrm{TC} * \mathrm{PEC} * \mathrm{SEC} .
$$

In this model, $D_{t}\left(x_{n}, y_{n}\right)$ represents the distance $D$ at time $t$ to the DMU represented by point $\left(x_{n}, y_{n}\right)$, with $x_{n}$ representing the inputs and $y_{n}$ representing the outputs, both at time $n$. The subindex $c$ in $D_{t}$, i.e., $D_{t}$, represents the distance $D$ at time $t$ of the DMU in the DEA model with a constant return to scale.

Considering the example with only one input and output, each distance can be graphically represented and, consequently, a clearer understanding of significance can be attained, as seen in Figure 2.

For TC and SEC, it is possible to infer that a value higher than 1 (one) means improvement, whereas a value lower than 1 (one) indicates worsening. Overall, this is also applied for the entire Malmquist Index:

$\mathrm{MI}>1 \longrightarrow$ there was an improvement between the compared periods

$\mathrm{MI}=1 \longrightarrow$ there was no improvement nor worsening between the compared periods

$\mathrm{MI}<=1 \longrightarrow$ there was worsening between the compared periods

In this study, the use of the Malmquist Index is justified because, in the period analyzed, the economic framework has changed-Brazil had left a scenery of $0.1 \%$ growth in 2014 to a retraction of $3.8 \%$ in 2015 . This provides us an opportunity for investigating the efficiency of public and private airports when the economic conditions deteriorate.

\subsection{Hirschman-Herfindahl Index (HHI).}

Herfindahl-Hirschman Index (HHI) is a measure of the size of firms in relation to the industry and an indicator of the level of competition among them. The HHI incorporates information about the number of firms in the market and the distribution of market share within the industry.

Independently proposed by both Hirschman [44, 45] and Herfindahl [46] as a measure of trade and industry concentration, the HHI has been used in the calculation of concentration across various contexts, ranging from household wealth or income, merger analysis, and firm outputs [47]:

$$
\mathrm{HHI}_{i}=\sum_{i=1}^{n} s_{i}^{2}
$$




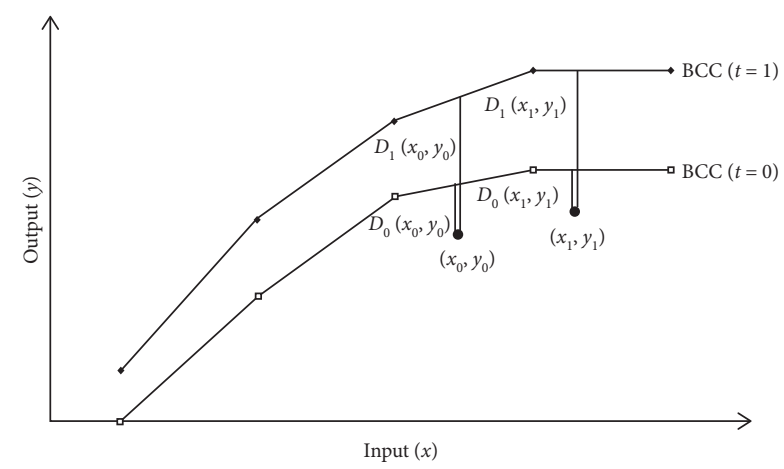

FIGURE 2: Representation of DEA BCC efficiency frontiers in two moments of time, as well as a DMU in two moments of time and its respective distances for each frontier (source: prepared by the authors).

Under monopoly, $n=1$ and $s 1=1$, so that $\mathrm{HHI}=1$ (max). Under perfect competition, $s_{\mathrm{i}}=1 / n, i=1,2, \ldots, n$, so $\mathrm{HHI}=1 / n(\mathrm{~min})$. So, the HHI moves within the range $1 /$ $n \leq \mathrm{HHI} \leq 1$. In this research, de HHI is used to evaluate changes in market concentration in the analyzed period comparing to the efficiency changes.

\section{Results and Discussion}

For comparatively analyzing the efficiency of public and private Brazilian airports, efficiencies were calculated by the two-stage DEA model presented in Section 2 of this study.

For each DMU, infrastructure (e1) and consolidation (e2) efficiencies were assessed through the two-stage DEA model adapted by Wanke [6] to study efficiency in airports. The author uses the following variable sets: total area of the airport, number of slots for aircraft, and number of runways are the inputs of the first stage; number of landings and takeoffs are the intermediate variable; and number of passengers transported and amount of cargo, in kilograms, transported are the outputs of the second stage.

Efficiency calculation was carried out in the software PIM-DEA ${ }^{\circledR}$, which calculated the weight values that optimize the two-stage DEA objective function for the data provided.

Table 1 shows the global efficiency values and their respective stages for each airport under study, calculated by DEA for 2014 and 2015. The "management" column indicates whether the DMU is managed by the government through INFRAERO $(G)$ or by public-private partnerships through concession regimes. In the column "Airport" are exhibited the names of the cities where the international airports are settled. The other columns present the percentage values for efficiency in each stage and the global efficiency in the two years studied. The following abbreviations were adopted: PIE for physical infrastructure efficiency, which represents the first stage of the DEA; FCE for flight consolidation efficiency, representing the second stage of the DEA; and GE for global efficiency.

In the airports granted to the private sector, almost $80 \%$ of the sample presents an efficiency greater than $70 \%$ in 2014, while only $40 \%$ of the sample presents an efficiency greater than $60 \%$ in 2015 . Another important aspect is that $78.6 \%$ of public airports have an efficiency below $50 \%$. In 1025, in turn, $92.9 \%$ of these airports had at least $50 \%$ of efficiency. Therefore, there seems to be a decreased efficiency from 2014 to 2015, for both management regimes. Nevertheless, it is noteworthy that the efficiency of private airports is higher than that of those managed by INFRAERO.

Below, descriptive and inferential statistical analyses are presented, which were performed from the global efficiency data to understand performance differences and resemblances among the airports under scrutiny.

Normality tests were also conducted for each of these datasets, to determine the most appropriate statistical procedures for the inferential analyses.

Finally, the results of comparative analyses within each dataset and between the $P$ and $G$ groups are presented.

4.1. Descriptive Statistics. This section presents a set of descriptive statistics for the variables used in the DEA model and the efficiency score. Table 2 shows minimum, maximum, mean values, and standard deviation for the inputs and outputs separated by year and type of management.

Descriptive statistics of position and dispersion were calculated for the efficiencies in 2014 and 2015 for the two datasets defined in the previous item. Tables 3 and 4 present these statistics.

It is noteworthy that, from the average values, there seems to be a significant difference between the values of government and private groups. However, further comparative tests are required to corroborate such hypothesis.

The values of the coefficient of variation indicate that the data dispersion is much greater in government airports than in private airports, especially regarding physical infrastructure efficiency, evidencing a different use of space between the groups.

The maximum global efficiency values of $100 \%$ indicated that, in the private group, there is at least one airport in the frontier that can be considered a benchmark of efficiency for the others. In the government group, although there is a maximum efficiency of $100 \%$ for both physical infrastructure and flight consolidation, the fact that the maximum global efficiency is less than $100 \%$ indicates that no DMU is simultaneous in both frontiers.

4.2. Normality Tests. To direct the choice of statistical procedures to be used in comparative analyses, the datasets were subjected to normality tests. Table 5 presents the results of the Kolmogorov-Smirnov and Shapiro-Wilk normality tests.

Normality tests indicate that only the FCE DEA measure shows consistent normality for both years and groups. Thus, this is the only measure that fits the assumptions of parametric statistical tests. However, given that the private group has only 5 DMUs, the sensitivity of type 2 error will be high if one applies parametric tests to this dataset. Therefore, we opted for using only nonparametric statistical data in the comparative analysis. 
TABLe 1: Physical infrastructure, flight consolidation, and global efficiencies (2014 and 2015).

\begin{tabular}{|c|c|c|c|c|c|c|}
\hline Airport & $\begin{array}{c}\text { PIE DEA } 2014 \\
(\%)\end{array}$ & $\begin{array}{c}\text { FCE DEA } 2014 \\
(\%)\end{array}$ & $\begin{array}{c}\text { GE DEA } 2014 \\
(\%)\end{array}$ & $\begin{array}{c}\text { PIE DEA } 2015 \\
(\%)\end{array}$ & $\begin{array}{c}\text { FCE DEA } 2015 \\
(\%)\end{array}$ & $\begin{array}{c}\text { GE DEA } 2015 \\
(\%)\end{array}$ \\
\hline Belém* & 81.10 & 60.89 & 47.48 & 77.98 & 59.87 & 28.43 \\
\hline Boa Vista* & 9.97 & 55.77 & 7.75 & 13.89 & 35.09 & 2.72 \\
\hline Campo Grande* & 19.69 & 55.86 & 10.33 & 18.49 & 56.80 & 5.87 \\
\hline Campos* & 100.00 & 6.42 & 6.42 & 100.00 & 7.45 & 0.48 \\
\hline Corumbá* & 5.28 & 100.00 & 5.08 & 5.08 & 100.00 & 5.08 \\
\hline Curitiba* & 100.00 & 76.41 & 76.41 & 100.00 & 75.58 & 57.75 \\
\hline Cuiabá* & 92.61 & 41.01 & 36.54 & 89.11 & 41.80 & 15.28 \\
\hline Cruzeiro do Sul* & 7.86 & 13.47 & 0.91 & 6.73 & 16.40 & 0.15 \\
\hline Manaus* & 48.33 & 100.00 & 41.37 & 41.37 & 100.00 & 41.37 \\
\hline Foz do Iguaçu* & 34.10 & 82.05 & 31.16 & 37.98 & 82.27 & 25.64 \\
\hline Florianópolis* & 65.61 & 57.71 & 34.73 & 60.18 & 61.28 & 21.28 \\
\hline Fortaleza* & 68.81 & 78.47 & 50.46 & 64.31 & 83.29 & 42.03 \\
\hline João Pessoa* & 23.41 & 86.30 & 23.05 & 26.71 & 84.79 & 19.54 \\
\hline Maceió* & 25.40 & 76.94 & 19.40 & 25.21 & 82.44 & 15.99 \\
\hline Macapá* & 15.21 & 47.07 & 5.50 & 11.69 & 54.76 & 3.01 \\
\hline Navegantes* & 100.00 & 53.82 & 53.82 & 100.00 & 55.86 & 30.06 \\
\hline Porto Alegre* & 100.00 & 70.43 & 70.43 & 100.00 & 72.04 & 50.74 \\
\hline Parnaíba* & 5.77 & 18.45 & 0.91 & 4.91 & 33.07 & 0.30 \\
\hline Pelotas* & 5.13 & 44.08 & 2.04 & 4.63 & 51.30 & 1.05 \\
\hline Petrolina* & 11.98 & 67.00 & 6.34 & 9.47 & 83.94 & 5.33 \\
\hline Porto Velho* & 21.74 & 45.44 & 8.88 & 19.55 & 51.54 & 4.58 \\
\hline Recife $^{*}$ & 100.00 & 76.49 & 76.49 & 100.00 & 73.23 & 56.01 \\
\hline S. J dos Campos* & 54.87 & 2.99 & 1.49 & 49.74 & 2.04 & 0.03 \\
\hline São Luís* & 19.59 & 65.34 & 12.05 & 18.44 & 63.97 & 7.71 \\
\hline Santarém* & 18.37 & 34.06 & 5.96 & 17.51 & 35.64 & 2.13 \\
\hline Salvador* & 81.38 & 68.99 & 52.65 & 76.32 & 73.41 & 38.65 \\
\hline Tabatinga* & 6.89 & 18.87 & 0.97 & 5.16 & 27.15 & 0.26 \\
\hline Vitória* & 100.00 & 45.93 & 45.93 & 100.00 & 46.78 & 21.49 \\
\hline Guarulhos** & 100.00 & 100.00 & 100.00 & 100.00 & 100.00 & 100.00 \\
\hline Brasília** & 100.00 & 75.82 & 75.82 & 100.00 & 78.94 & 59.85 \\
\hline Campinas** & 100.00 & 82.98 & 82.98 & 100.00 & 74.74 & 62.02 \\
\hline Rio de Janeiro** & 64.88 & 94.66 & 59.09 & 62.42 & 96.56 & 57.05 \\
\hline Belo Horizonte ${ }^{* *}$ & 100.00 & 77.73 & 77.73 & 100.00 & 77.04 & 59.88 \\
\hline
\end{tabular}

TABle 2: Descriptive statistics of inputs and outputs by year.

\begin{tabular}{|c|c|c|c|c|c|c|}
\hline Management & Year & Inputs/outputs & Min. & Max. & Mean & Std. deviation \\
\hline \multirow{6}{*}{ Public } & \multirow{3}{*}{2014} & Total movements & 1747.00 & 107255.00 & 33936.03 & 30624.07 \\
\hline & & Total passengers & 19341.00 & 9574662.00 & 2599763.07 & 2897140.19 \\
\hline & & Total cargo & 8.00 & 142532.00 & 14581.25 & 28490.81 \\
\hline & \multirow{3}{*}{2015} & Total movements & 1670.00 & 97139.00 & 31834.39 & 28607.65 \\
\hline & & Total passengers & 19968.00 & 9385173.00 & 2546421.25 & 2806521.04 \\
\hline & & Total cargo & 11.00 & 112331.00 & 12307.35 & 22880.76 \\
\hline \multirow{6}{*}{ Private } & \multirow{3}{*}{2014} & Total movements & 107307.00 & 304559.00 & 173548.40 & 78290.95 \\
\hline & & Total passengers & 9846853.00 & 39765714.00 & 19162302.00 & 12103542.50 \\
\hline & & Total cargo & 27826.00 & 554663.00 & 192899.80 & 216694.68 \\
\hline & \multirow{3}{*}{2015} & Total movements & 113527.00 & 295030.00 & 171030.20 & 74641.14 \\
\hline & & Total passengers & 10324658.00 & 39213865.00 & 19503873.40 & 11649087.01 \\
\hline & & Total cargo & 35572.00 & 526012.00 & 179339.60 & 203032.47 \\
\hline
\end{tabular}

4.3. Comparative Analyses. When comparatively analyzing both DEA stages through a graph, as shown in Figures 3 and 4 , the first conclusion that can be made is that the private airports are all above the median line in any of the stages.

It is also possible to note a smaller number of DMUs with $100 \%$ efficiency in the one-stage DEA. In both 2014 and 2015 , it is noteworthy that only one unit is in the efficiency frontier. Finally, one can see that the same ten DMUs are above the medians in both years.

To test whether there is a significant difference between group $G$ and $P$ efficiencies, nonparametric hypothesis tests were performed through the Mann-Whitney $U$-test for independent samples. Table 6 shows the results of the global efficiency tests and their respective stages in each year. 
Table 3: Descriptive statistics by year and dataset Government.

\begin{tabular}{lcccccc}
\hline & PIE DEA 2014 & FCE DEA 2014 & GE DEA 2014 & PIE DEA 2015 & FCE DEA 2015 & GE DEA 2015 \\
\hline Average & 47.25 & 55.37 & 26.23 & 45.87 & 57.56 & 17.96 \\
Confidence interval (95\%) & & & & & \\
$\quad$ Inferior & 32.66 & 45.12 & 16.60 & 31.41 & 47.48 & 10.75 \\
$\quad$ Superior & 61.85 & 65.61 & 35.87 & 60.34 & 67.65 & 25.17 \\
Median & 29.75 & 56.79 & 15.72 & 32.35 & 58.34 & 11.49 \\
Variance & 1416.66 & 698.54 & 617.14 & 1392.26 & 676.73 & 345.61 \\
Standard deviation & 37.64 & 26.43 & 24.84 & 37.31 & 26.01 & 18.59 \\
Coefficient of variation & $79.65 \%$ & $47.74 \%$ & $94.69 \%$ & $81.34 \%$ & $45.19 \%$ & $103.50 \%$ \\
Minimum & 5.13 & 2.99 & 0.91 & 4.63 & 2.04 & 0.03 \\
Maximum & 100.00 & 100.00 & 76.49 & 100.00 & 100.00 & 57.75 \\
Asymmetry & 0.362 & -0.375 & 0.720 & 0.422 & -0.411 & 0.866 \\
Kurtosis & -1.627 & -0.460 & -0.754 & -1.517 & -0.389 & -0.470 \\
\hline
\end{tabular}

Table 4: Descriptive statistics by year and dataset Private.

\begin{tabular}{lcccccc}
\hline & PIE DEA 2014 & FCE DEA 2014 & GE DEA 2014 & PIE DEA 2015 & FCE DEA 2015 & GE DEA 2015 \\
\hline Average & 92.98 & 86.24 & 79.12 & 92.48 & 85.46 & 67.76 \\
Confidence interval (95\%) & & & & & \\
$\quad$ Inferior & 73.47 & 73.04 & 60.86 & 71.62 & 70.73 & 45.28 \\
$\quad$ Superior & 112.48 & 99.43 & 97.38 & 113.35 & 100.19 & 90.25 \\
Median & 100.00 & 82.98 & 77.73 & 100.00 & 78.94 & 59.88 \\
Variance & 246.68 & 112.96 & 216.25 & 282.45 & 140.74 & 327.89 \\
Standard deviation & 15.71 & 10.63 & 14.71 & 16.81 & 11.86 & 18.11 \\
Coefficient of variation & $16.89 \%$ & $12.32 \%$ & $18.59 \%$ & $18.17 \%$ & $7.88 \%$ & $26.72 \%$ \\
Minimum & 64.88 & 75.82 & 59.09 & 62.42 & 74.74 & 57.05 \\
Maximum & 100.00 & 100.00 & 100.00 & 100.00 & 100.00 & 100.00 \\
Asymmetry & -2.236 & 0.494 & 0.141 & -2.236 & 0.585 & 2.183 \\
Kurtosis & 5.000 & -2.315 & 1.394 & 5.000 & -2.954 & 4.814 \\
\hline
\end{tabular}

TABle 5: Normality tests for DEA efficiency values.

\begin{tabular}{lcccccrrr}
\hline \multirow{2}{*}{ Efficiency data } & \multicolumn{4}{c}{ Government } & \multicolumn{2}{c}{ Private } \\
& \multicolumn{2}{c}{ Kolmogorov-Smirnov } & \multicolumn{2}{c}{ Shapiro-Wilk } & \multicolumn{2}{c}{ Kolmogorov-Smirnov } & \multicolumn{2}{c}{ Shapiro-Wilk } \\
& Statistics & Sig. & Statistics & Sig. & Statistics & Sig. & Statistics & Sig. \\
\hline PIE DEA 2014 & 0.219 & 0.001 & 0.834 & 0.000 & 0.473 & 0.001 & 0.552 \\
FCE DEA 2014 & 0.095 & 0.200 & 0.963 & 0.403 & 0.220 & 0.200 & 0.899 & 0.000 \\
GE DEA 2014 & 0.216 & 0.002 & 0.864 & 0.002 & 0.211 & 0.200 & 0.967 \\
PIE DEA 2015 & 0.196 & 0.007 & 0.841 & 0.001 & 0.473 & 0.001 & 0.552 \\
FCE DEA 2015 & 0.104 & 0.200 & 0.967 & 0.511 & 0.309 & 0.135 & 0.821 \\
GE DEA 2015 & 0.209 & 0.003 & 0.856 & 0.001 & 0.424 & 0.004 & 0.644 \\
\hline
\end{tabular}

Hypothesis testing indicates a significant difference between the efficiencies of the $P$ and $G$ groups for all values tested. Along with the data presented in Tables 2 and 3, this allows one to conclude that the set of Brazilian airports managed by private companies exhibited higher efficiency in 2014 and 2015 than airports operated by the government, for the three types of efficiency analyzed in this study (PIE, FCE, and GE).

4.4. Malmquist Index Analysis. To ascertain how the efficiency of each airport has changed regarding the frontier in both periods analyzed, the Malmquist Index (MI) was calculated. Table 7 shows the values calculated for the index in each DEA stage: the first, on physical infrastructure (PIE $\mathrm{MI}$ ), and the second, on flight consolidation (FCE MI).
Among the private airports, Campinas was the only one with worsening from 2014 to 2015, in both physical infrastructure and flight consolidation efficiencies. The Rio de Janeiro airport presented contradictory values, with improved flight consolidation efficiency and worst physical structure. The other maintained their performances or somewhat improved in both stages.

Concerning government-managed airports, in $75 \%$ of the DMUs, the physical infrastructure efficiency worsened, and in $18 \%$, the flight consolidation efficiency deteriorated. The airports of Campos, Foz do Iguaçu, João Pessoa, Navegantes, Porto Alegre, and Vitória were the only ones with improved values in both indexes. On the other hand are the airports of Pelotas, Recife, São José dos Campos, and São Luís, which presented a worsening in both indexes. It is worth noting that the Boa Vista airport showed a significant 


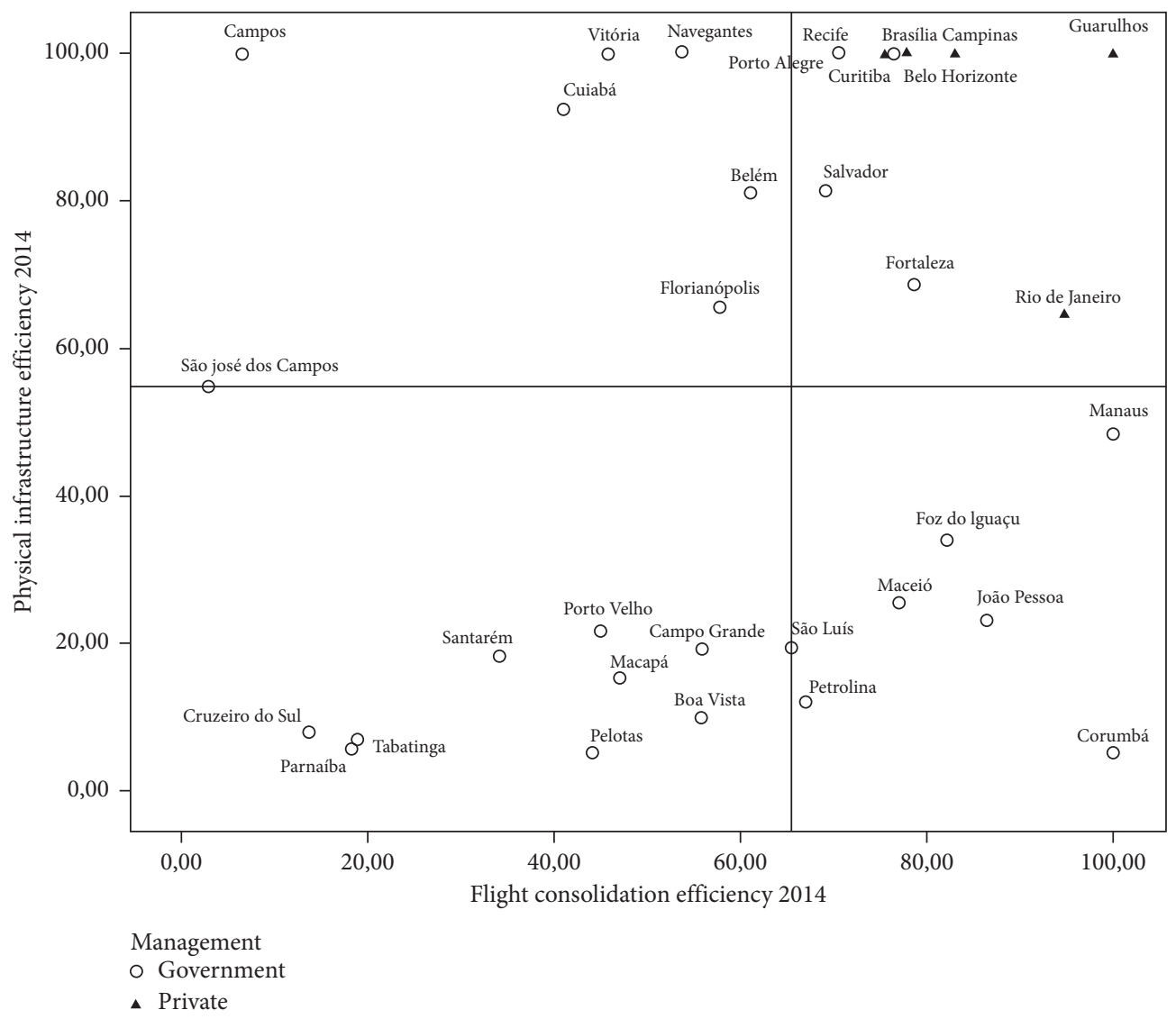

Figure 3: Comparison between the DEA stages, 2014.

improvement in the use of infrastructure but a worsening in flight consolidation.

Table 8 presents the descriptive statistics for the Malmquist Indexes for groups $P$ and $G$.

From the MI evaluation for the first stage, it is possible to conclude that the physical infrastructure efficiency has worsened, as the mean index is 0.95 . This indicates that the airports have a worse use of their physical space. Such fact is clearer in examples such as Tabatinga, Petrolina, and Macapá, with MI below 0.80, and airports such as Parnaíba, Cruzeiro do Sul, Pelotas, São José dos Campos, and Manaus, with MI below 0.90. All listed airports have inputs and outputs below the sample average, except for Manaus, and little alterations have a high impact on their efficiency changes.

A similar situation occurs for the positive examples: Boa Vista, João Pessoa, Foz do Iguaçu, and Confins have a MI above 1, characterizing improvement. Among these, only Belo Horizonte has inputs and outputs above the sample average. Largest airports such as Guarulhos, Brasília, Rio de Janeiro, and Campinas presented little data variation and, consequently, their indexes were close to 1. Along with Belo Horizonte, these four units belong to the group of the privatized airports, which, due to a lower relative (percentage) data variation, have indexes close to 1 , with a mean of 0.99 and standard deviation of 0.03 .
On the other hand, the 28 public airports in the sample presented much more varied sizes and, consequently, greater variation in the Malmquist Index, with a mean of 0.94 and a standard deviation of 0.12 . Finally, we observed that the number of landings and takeoffs, the only factor that varies on the DEA first stage data, represents almost all the variation of the Malmquist Index.

However, the MI for the second stage presents a mean of 1.05 , showing improvement in flight consolidation. In this second stage, all three factors-one input and two outputs-vary for all airports, none of them having a considerable impact on the index. Only São José dos Campos, Boa Vista, and Campinas worsened in flight consolidation efficiency, and only the latter had above-average indicators. The first is penalized by a considerable decrease in passenger flow ( $41 \%$ reduction), whereas the second is penalized by an increased number of landings and takeoffs (37\% rise).

Of the seven airports with MI above 1.10, five (Macapá, Cruzeiro do Sul, Petrolina, Tabatinga, and Parnaíba) had at least $15 \%$ reduction in the number of landings and takeoffs, and the other two (Porto Velho and Campos) had diverse variations in inputs and outputs. Again, the largest airports, whose volume variation is less expressed in percentage, have MI close to 1 , evidencing little changes in efficiency from one year to the next.

Within this criterion of largest airports are the five private airports, and thus, they present little variation in the Malmquist Index, with an average of 1.01 and standard 


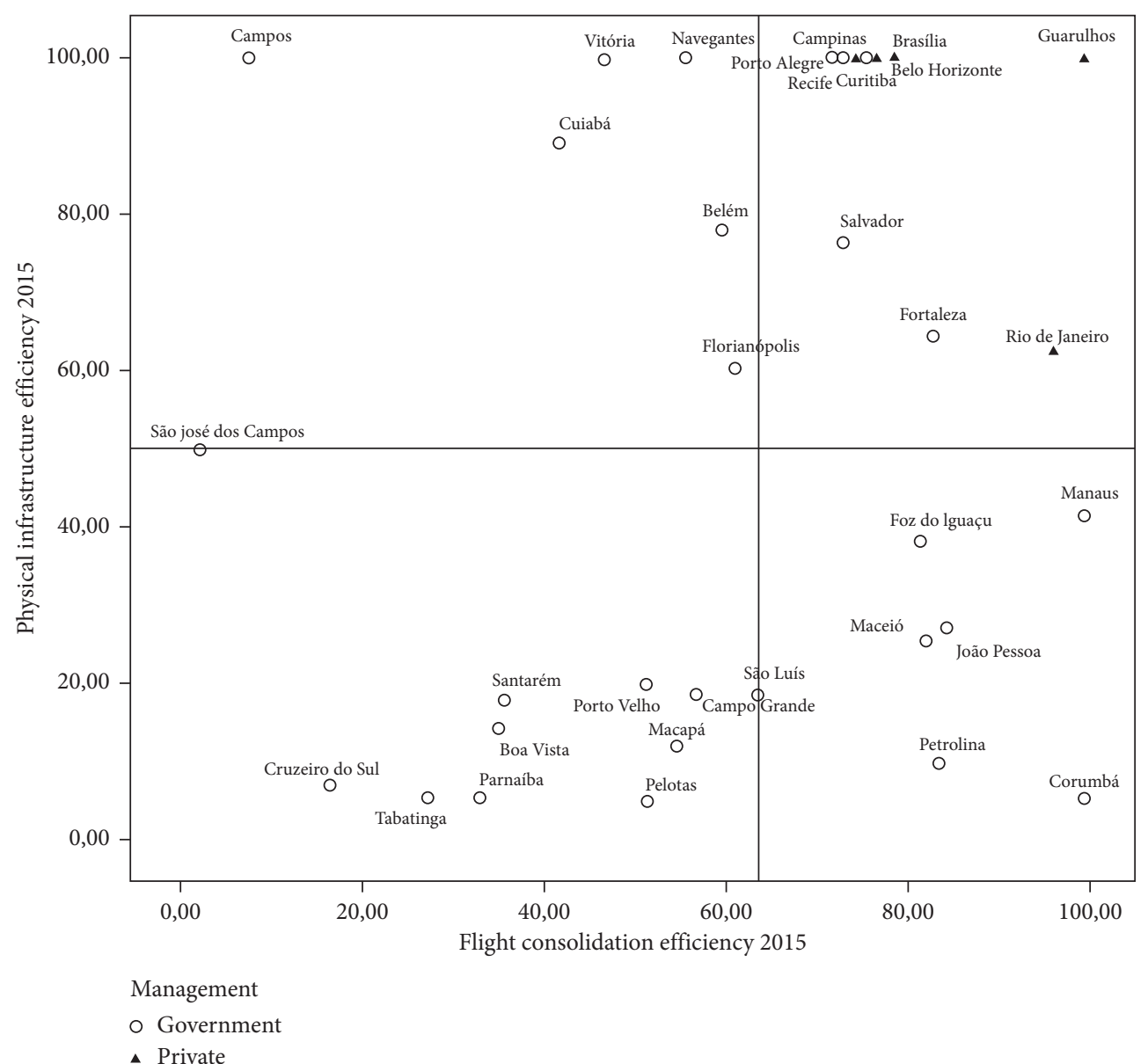

Figure 4: Comparison between the DEA stages, 2015.

TABLE 6: Hypotheses testing for the DEA efficiency averages.

\begin{tabular}{lccr}
\hline & Mann-Whitney $U$ & Standard error & Sig. \\
\hline PIE DEA 2014 & 117 & 19.640 & 0.017 \\
FCE DEA 2014 & 121 & 19.910 & 0.010 \\
GE DEA 2014 & 135 & 19.916 & 0.001 \\
PIE DEA 2015 & 118 & 19.640 & 0.015 \\
FCE DEA 2015 & 115 & 19.910 & 0.024 \\
GE DEA 2015 & 139 & 19.916 & 0.001 \\
\hline
\end{tabular}

TABLe 7: Malmquist Indexes for PIE DEA and FCE DEA.

\begin{tabular}{lccc}
\hline Management & Airport & PIE MI & FCE MI \\
\hline$G$ & Belém & 0.94 & 1.00 \\
$G$ & Boa Vista & 1.37 & 0.70 \\
$G$ & Campo Grande & 0.92 & 1.03 \\
$G$ & Campos & 1.00 & 1.18 \\
$G$ & Corumbá & 0.96 & 1.02 \\
$G$ & Curitiba & 0.97 & 1.01 \\
$G$ & Cuiabá & 0.96 & 1.04 \\
$G$ & Cruzeiro do Sul & 0.86 & 1.19 \\
$G$ & Manaus & 0.88 & 1.00 \\
$G$ & Foz do Iguaçu & 1.06 & 1.03 \\
$G$ & Florianópolis & 0.93 & 1.08 \\
$G$ & Fortaleza & 0.90 & 1.08 \\
\hline
\end{tabular}


TABLE 7: Continued.

\begin{tabular}{lccc}
\hline Management & Airport & PIE MI & FCE MI \\
\hline$G$ & João Pessoa & 1.10 & 0.95 \\
$G$ & Maceió & 0.77 & 1.02 \\
$G$ & Macapá & 1.00 & 1.15 \\
$G$ & Navegantes & 1.00 & 1.06 \\
$G$ & Porto Alegre & 0.82 & 1.04 \\
$G$ & Parnaíba & 0.86 & 1.26 \\
$G$ & Pelotas & 0.76 & 0.99 \\
$G$ & Petrolina & 0.92 & 1.19 \\
$G$ & Porto Velho & 0.96 & 1.15 \\
$G$ & Recife & 0.87 & 0.97 \\
$G$ & São José dos Campos & 0.91 & 0.92 \\
$G$ & São Luís & 0.92 & 0.91 \\
$G$ & Santarém & 0.74 & 1.99 \\
$G$ & Salvador & 1.00 & 1.06 \\
$G$ & Tabatinga & 1.00 & 1.08 \\
$G$ & Vitória & 1.00 & 1.04 \\
$P$ & Guarulhos & 0.97 & 1.00 \\
$P$ & Brasília & 0.95 & 1.06 \\
$P$ & Campinas & 1.03 & 0.92 \\
$P$ & Rio de Janeiro & 1.04 \\
$P$ & Belo Horizonte & 1.01 \\
\hline
\end{tabular}

Table 8: Descriptive statistics of the Malmquist Indexes.

\begin{tabular}{|c|c|c|c|c|}
\hline & PIE MI $(G)$ & FCE MI $(G)$ & PIE MI $(P)$ & FCE MI $(P)$ \\
\hline Average & 0.9371 & 1.0496 & 0.9900 & 1.0060 \\
\hline \multicolumn{5}{|l|}{ Confidence interval (95\%) } \\
\hline Inferior & 0.8910 & 1.0001 & 0.9517 & 0.9394 \\
\hline Superior & 0.9833 & 1.0991 & 1.0283 & 1.0726 \\
\hline Median & 0.9250 & 1.0400 & 1.0000 & 1.0100 \\
\hline Variance & 0.014 & 0.016 & 0.001 & 0.003 \\
\hline Standard deviation & 0.11910 & 0.12764 & 0.03082 & 0.05367 \\
\hline Coefficient of variation (\%) & 12.71 & 12.16 & 3.11 & 5.33 \\
\hline Minimum & 0.74 & 0.69 & 0.95 & 0.92 \\
\hline Maximum & 1.37 & 1.26 & 1.03 & 1.06 \\
\hline Asymmetry & 1.590 & -1.214 & -0.085 & -1.185 \\
\hline Kurtosis & 5.758 & 3.015 & -0.659 & 1.727 \\
\hline
\end{tabular}

deviation of 0.05 . Once again, public airports had a greater MI variation, with an average of 1.05 and standard deviation of 0.13 , due to the fact they present size and volume discrepancies and, consequently, greater MI fluctuation. Overall, one can observe that private airports have shown little improvement or worsening, with a mean close to 1 and low standard deviation in both stages, whereas public airports worsened in the first stage and improved in the second, at the same time that they present a quite significant variation, represented by the standard deviation.

That being said, after the initial analyses, Table 9 presents the results of the Kolmogorov-Smirnov and Shapiro-Wilk normality tests for the Malmquist Indexes.

The normality tests indicate that the data in group $P$ can be considered normal, but the data in group $G$ cannot. However, similarly to what was presumed for the DEA efficiency data, only nonparametric tests were performed because there is only 5 MDUs in group $P$.
Table 10 presents the results of the tests for the Malmquist Indexes.

At a 5\% significance level, hypothesis tests show no significant difference between the Malmquist Indexes of groups $P$ and $G$ for the values analyzed, which allows one to infer that the development of private and government airports was similar from 2014 to 2015 . Nonetheless, at a $10 \%$ significance level, it is possible to affirm that there is a difference between the groups regarding physical structure efficiency.

4.5. Hirschman-Herfindahl Index (HHI) Results. According to Sugiyanto et al. [48], the Hirschman-Herfindahl Index is a meaningful measure on how well the on-demand air service (ODAS) network meets the travel demand is the transport efficiency. In addition, HHI shows if there is any evidence of market concentration. The results for this index are presented in Table 11. 
TABLe 9: Normality tests for the Malmquist Indexes.

\begin{tabular}{lcccccrrr}
\hline & \multicolumn{4}{c}{ Government } & \multicolumn{2}{c}{ Private } \\
Efficiency & \multicolumn{2}{c}{ Kolmogorov-Smirnov } & \multicolumn{2}{c}{ Shapiro-Wilk } & \multicolumn{2}{c}{ Kolmogorov-Smirnov } & \multicolumn{2}{c}{ Shapiro-Wilk } \\
& Statistics & Sig. & Statistics & Sig. & Statistics & Sig. & Statistics & Sig. \\
\hline PIE MI & 0.192 & 0.010 & 0.866 & 0.002 & 0.227 & 0.200 & 0.960 \\
FCE MI & 0.213 & 0.002 & 0.857 & 0.001 & 0.255 & 0.200 & 0.916 & 0.511 \\
\hline
\end{tabular}

TABle 10: Hypotheses testing for the Malmquist Indexes.

\begin{tabular}{lccc}
\hline & Mann-Whitney $U$ & Standard error & Sig. \\
\hline PIE MI & 108 & 19.838 & 0.055 \\
FCE MI & 45 & 19.870 & 0.208 \\
\hline
\end{tabular}

TABle 11: Hirschman-Herfindahl Index.

\begin{tabular}{|c|c|c|c|c|c|}
\hline Airport & PAX_2014 & HHI_2014 & PAX_2015 & HHI_2015 & Variation \\
\hline Guarulhos** & 0.2359 & 0.0556 & 0.2323 & 0.0540 & $-3.00 \%$ \\
\hline Brasília** $^{* *}$ & 0.1076 & 0.0116 & 0.1155 & 0.0133 & $15.24 \%$ \\
\hline Galeão** & 0.1024 & 0.0105 & 0.1004 & 0.0101 & $-3.91 \%$ \\
\hline Confins ${ }^{* *}$ & 0.0640 & 0.0041 & 0.0683 & 0.0047 & $13.95 \%$ \\
\hline Viracopos ${ }^{* *}$ & 0.0584 & 0.0034 & 0.0612 & 0.0037 & $9.66 \%$ \\
\hline Salvador* & 0.0568 & 0.0032 & 0.0556 & 0.0031 & $-4.16 \%$ \\
\hline Porto Alegre* & 0.0501 & 0.0025 & 0.0495 & 0.0025 & $-2.51 \%$ \\
\hline Curitiba* & 0.0460 & 0.0021 & 0.0444 & 0.0020 & $-6.60 \%$ \\
\hline Recife* & 0.0440 & 0.0019 & 0.0409 & 0.0017 & $-13.47 \%$ \\
\hline Fortaleza* & 0.0410 & 0.0017 & 0.0396 & 0.0016 & $-6.77 \%$ \\
\hline Belém* & 0.0255 & 0.0006 & 0.0238 & 0.0006 & $-12.73 \%$ \\
\hline Florianópolis* & 0.0221 & 0.0005 & 0.0223 & 0.0005 & $1.45 \%$ \\
\hline Manaus* & 0.0211 & 0.0004 & 0.0202 & 0.0004 & $-8.28 \%$ \\
\hline Vitória* & 0.0210 & 0.0004 & 0.0212 & 0.0005 & $2.43 \%$ \\
\hline Cuiabá* & 0.0201 & 0.0004 & 0.0200 & 0.0004 & $-0.94 \%$ \\
\hline São Luís* & 0.0124 & 0.0002 & 0.0112 & 0.0001 & $-18.65 \%$ \\
\hline Maceió $^{*}$ & 0.0114 & 0.0001 & 0.0118 & 0.0001 & $8.04 \%$ \\
\hline Foz do Iguaçu* & 0.0111 & 0.0001 & 0.0121 & 0.0001 & $19.31 \%$ \\
\hline Campo Grande* & 0.0102 & 0.0001 & 0.0096 & 0.0001 & $-10.22 \%$ \\
\hline Navegantes* & 0.0081 & 0.0001 & 0.0088 & 0.0001 & $20.25 \%$ \\
\hline João Pessoa* & 0.0079 & 0.0001 & 0.0089 & 0.0001 & $25.00 \%$ \\
\hline Porto Velho* & 0.0057 & 0.0000 & 0.0061 & 0.0000 & $12.43 \%$ \\
\hline Santarém* & 0.0048 & 0.0000 & 0.0047 & 0.0000 & $-4.97 \%$ \\
\hline Macapá* & 0.0044 & 0.0000 & 0.0039 & 0.0000 & $-21.33 \%$ \\
\hline Petrolina* & 0.0031 & 0.0000 & 0.0028 & 0.0000 & $-17.42 \%$ \\
\hline Boa Vista* & 0.0022 & 0.0000 & 0.0021 & 0.0000 & $-9.25 \%$ \\
\hline Campos* & 0.0010 & 0.0000 & 0.0011 & 0.0000 & $27.73 \%$ \\
\hline Tabatinga* & 0.0004 & 0.0000 & 0.0004 & 0.0000 & $-14.17 \%$ \\
\hline Cruzeiro do Sul* & 0.0004 & 0.0000 & 0.0004 & 0.0000 & $4.11 \%$ \\
\hline Pelotas* & 0.0003 & 0.0000 & 0.0003 & 0.0000 & $-27.02 \%$ \\
\hline S. J. dos Campos* & 0.0003 & 0.0000 & 0.0002 & 0.0000 & $-64.82 \%$ \\
\hline Corumbá* & 0.0002 & 0.0000 & 0.0002 & 0.0000 & $-4.26 \%$ \\
\hline Parnaíba* & 0.0001 & 0.0000 & 0.0001 & 0.0000 & $6.32 \%$ \\
\hline
\end{tabular}

Table 10 results show that there is no indication of a monopoly, oligopoly, or cartel that is highlighted by the HHI. Other relevant results presented in Table 10 are the difference between the years 2014 and 2015 which is very low. It is worth mentioning that Guarulhos airport lost a little competitiveness in 2015 compared to 2014. It is also worth mentioning that private airports have much more concentration than public ones in the order of 17 times more compared to the best private airport with the best public one.
Another important issue that must be addressed is that no strong correlation was found between the $\mathrm{HH}$ index and the score DEA. The biggest value encountered was 0.34 between consolidation efficiency and HHI in 2014. Thus, there is no evidence that most efficient airports have more market concentration.

The variations in HHI between 2014 and 2015 are quite different between the airports in the sample, ranging from $27.73 \%$ to $-64.82 \%$. It is important to remember that Brazil 
is a country with continental dimensions and very different economic levels among the different states that have airports in the sample. Thus, it is to be expected that the crisis that hits the country will have different effects on the market concentration of the airports, probably due to economic factors in each state. However, when observing these variations and comparing them with the Malmquist Indexes from Table 7, it is possible to notice that, although the correlation levels are low (Pearson's coefficient of -0.099 and 0.307 for physical infrastructure and for consolidation of flights efficiencies, respectively), 18 of the 33 airports in the sample worsened their physical infrastructure efficiencies when market concentration decreased (negative variation) and 11 airports improved their flight consolidation efficiency when their concentration levels increased.

These results may indicate that the decrease in market concentration, by reducing the demand from the airport (less movement of aircraft at the exit of the first stage), tends to reduce its efficiency in the use of infrastructure since it has remained fixed in the two years of the study. Likewise, it is possible that less movement will be more difficult for some airports to consolidate cargo and passengers, worsening their performance in the second stage of the model. Due to the heterogeneity of the airports in the sample, these impacts were more felt in some than in others.

These results refute the hypothesis that there is a correlation between market concentration and efficiency, which can be explained by two arguments. The first is that the model used is a BCC, which "penalizes" airports with a larger scale allowing them to be compared to smaller ones; thus, gains from market concentration are possibly not reflected in the DEA score. The second argument to be considered is that, in this study, it was analyzed a developing market, in which, according to Nguyen et al. [49], the relationship between efficiency and market share or market share gains is not identified.

\section{Conclusions}

This study sought to comparatively analyze the efficiency of public and private Brazilian international airports under two mathematical approaches of efficiency calculation: the twostage DEA and the Malmquist Index. To do so, secondary data of 2014 and 2015 were used, obtained from the Airports Council International (ACI).

Results indicate a decreased efficiency of the airports studied and show sufficient evidence to state that the performance of airports under concession to the private sector is superior to that of those run by the government.

The airports managed by INFRAERO had a worsening in global efficiency between 2014 and 2015. However, most private airports remained efficient or improved their performances between these years. This is a very important aspect to be highlighted because in 2014 Brazil enters a cycle of economic recession, with a $3.8 \%$ retraction in the 2015 GDP. These results allowed us to conclude that the private airports, in addition to being more efficient, also proved to be more resilient regarding the efficiency performance in a period of economic crisis.

Nevertheless, the performance of some public airports draws attention, such as the cases of Campos and Curitiba, which are on the frontier of infrastructure efficiency, as well as Corumbá and Manaus, which are on the efficiency frontier for flight consolidation, in both periods analyzed. Such results show that, to some extent, some public airports have elements that equate them to private airports; hence, an investigation of INFRAERO to identify and disseminate them to the other airports would be convenient.

Also, considering the results found in previous works, the findings of this research support the line of studies where the form of ownership/management influences the airport performance regarding its efficiency. The results obtained in this study are similar to works such as Perelman and Serebrisky [19], Adler et al. [20], and Chen and Lai [21] which state that private ownership/managed airports tend to be more efficient than public ones. However, in this work, we present some differences, which we think that can contribute to improve the understanding over the effects of the form of ownership/ management by showing that private airports are more efficient than public ones both in the use of its infrastructure and in the ability to consolidate flights.

Thus, considering this context, it is important to make suggestions for future works, seeking to expand the comprehension of airport efficiency issues. First, it is possible to use the same theoretical model (Figure 1) with other frontier analysis techniques, such as slack-based measures (SBM), stochastic frontier analysis (SFA), or super efficiency in order to evaluate the consistency of the results and determine the most suitable technique to this kind of research. Second, it should be possible to identify the determinants of efficiency on airports if a series of case studies were realized, comparing airports considered to be benchmarks with nonefficient ones. Third, it is possible to address the same research problem but considering all the Latin American airports and comparing subsamples in each country. Results provided for such works could be insightful to understand the efficiency performance over the countries and also support public policies that could help to improve the logistics and the economy of the continent.

We expect the results obtained by this study can contribute to discussions in the academia on this subject, since the scientific literature of the area presents a growing interest for the efficiency analysis in airports around the world and possibly as a subsidy to support the development of public policies and management decisions in the airports of the country.

\section{Data Availability}

The database was purchased from Airports Council International (ACI). To have access, the researchers must get in touch with this organization and acquire the data. 


\section{Conflicts of Interest}

The authors declare that they have no conflicts of interest.

\section{Acknowledgments}

We thank the São Paulo Research Foundation (FAPESP) for financing this research (process 2016/08970-7) and the School of Applied Sciences (FCA) of the State University of Campinas (UNICAMP) for providing infrastructure.

\section{References}

[1] Air Transport Action Group (ATAG), The Economic \& Social Benefits of Air Transportation, ATAG, Geneva, Switzerland, 2014.

[2] C.-C. Chao and P.-C. Yu, "Quantitative evaluation model of air cargo competitiveness and comparative analysis of major Asia-Pacific airports," Transport Policy, vol. 30, no. 1, pp. 318-326, 2013.

[3] Boeing, Current Market Outlook 2009-2028, Boeing, Chicago, IL, USA, 2010.

[4] A. G. Assaf, D. Gillen, and C. Barros, "Performance assessment of UK airports: Evidence from a Bayesian dynamic frontier model," Transportation Research Part E: Logistics and Transportation Review, vol. 48, no. 3, pp. 603-615, 2012.

[5] M. Weiszer, J. Chen, and G. Locatelli, "An integrated optimisation approach to airport ground operations to foster sustainability in the aviation sector," Applied Energy, vol. 157, pp. 567-582, 2015.

[6] P. F. Wanke, "Physical infrastructure and flight consolidation efficiency drivers in Brazilian airports: A two-stage networkDEA approach," Journal of Air Transport Management, vol. 31, pp. 1-5, 2013.

[7] R. Merkert and L. Mangia, "Efficiency of Italian and Norwegian airports: A matter of management or of the level of competition in remote regions?" Transportation Research Part A: Policy and Practice, vol. 62, pp. 30-38, 2014.

[8] T.-w. Chung, W.-c. Ahn, S.-m. Jeon, and V. Van Thai, "A benchmarking of operational efficiency in Asia Pacific international cargo airports," The Asian Journal of Shipping and Logistics, vol. 31, no. 1, pp. 85-108, 2015.

[9] V. Fasone and S. Zapata-Aguirre, "Measuring business performance in the airport context: A critical review of literature," International Journal of Productivity and Performance Management, vol. 65, no. 8, pp. 1137-1158, 2016.

[10] S. X. H. Gong, K. Cullinane, and M. Firth, "The impact of airport and seaport privatization on efficiency and performance: A review of the international evidence and implications for developing countries," Transport Policy, vol. 24, no. 1, pp. 37-47, 2012.

[11] T. H. Oum, N. Adler, and C. Yu, "Privatization, corporatization, ownership forms and their effects on the performance of the world's major airports," Journal of Air Transport Management, vol. 12, no. 3, pp. 109-121, 2006.

[12] B. Zou, N. Kafle, Y.-T. Chang, and K. Park, "US airport financial reform and its implications for airport efficiency: An exploratory investigation," Journal of Air Transport Management, vol. 47, no. 1, pp. 66-78, 2015.

[13] C. Lo Storto, "Ownership structure and the technical, cost, and revenue efficiency of Italian airports," Utilities Policy, vol. 50, no. 1, pp. 175-193, 2018.
[14] F. Carlucci, A. Cirà, and P. Coccorese, "Measuring and explaining airport efficiency and sustainability: Evidence from Italy," Sustainability, vol. 10, no. 2, pp. 1-17, 2018.

[15] D. C. Ferreira, R. C. Marques, and M. I. Pedro, "Comparing efficiency of holding business model and individual management model of airports," Journal of Air Transport Management, vol. 57, no. 1, pp. 168-183, 2016.

[16] V. Liebert and H. M. Niemeier, "A survey of empirical research on the productivity and efficiency measurement of airports," Journal of Transport Economics, vol. 47, no. Part 2, pp. 157-189, 2013.

[17] P. Malighetti, G. Martini, S. Paleari, and R. Redondi, "An empirical investigation on the efficiency, capacity and ownership of Italian airports," Review di Political Economy, vol. I, no. II, pp. 157-188, 2007.

[18] S. Gitto and P. Mancuso, "Bootstrapping the Malmquist indexes for Italian airports," International Journal of Production Economics, vol. 135, no. 1, pp. 403-411, 2012.

[19] S. Perelman and T. Serebrisky, "Measuring the technical efficiency of airports in Latin America," Utilities Policy, vol. 22, no. 1, pp. 1-7, 2012.

[20] N. Adler, V. Liebert, and E. Yazhemsky, "Joint impact of competition, ownership form and economic regulation on airport performance and pricing," Transportation Research Part A: Policy and Practice, vol. 64, no. 1, pp. 92-109, 2014.

[21] Y.-H. Chen and P.-L. Lai, "Determining the relationship between ownership and technical efficiency by using a dynamic stochastic production frontier approach," Journal of Air Transport Management, vol. 75, no. 1, pp. 61-67, 2019.

[22] T. H. Oum, J. Yan, and C. Yu, "Ownership forms matter for airport efficiency: A stochastic frontier investigation of worldwide airports," Journal of Urban Economics, vol. 64, no. 2, pp. 422-435, 2008.

[23] C. Curi, S. Gitto, and P. Mancuso, "The Italian airport industry in transition: a performance analysis," Journal of Air Transport Management, vol. 16, no. 4, pp. 218-221, 2010.

[24] G. Martini, D. Scotti, and N. Volta, "Including local air pollution in airport efficiency assessment: a hyperbolic-stochastic approach," Transportation Research Part D: Transport and Environment, vol. 24, no. 1, pp. 27-36, 2013.

[25] E. Gutiérrez and S. Lozano, "Efficiency assessment and output maximization possibilities of European small and medium sized airports," Research in Transportation Economics, vol. 56, no. 1, pp. 3-14, 2016.

[26] E. P. Paraschi, A. Georgopoulos, and A. Papatheodorou, "Abiotic determinants of airport performance: Insights from a global survey," Transport Policy, vol. 85, no. 1, pp. 33-53, 2020.

[27] D. Parker, "The performance of BAA before and after privatization: A DEA study," Journal of Transport Economics and Policy, vol. 33, no. 2, pp. 133-145, 1999.

[28] T. H. Oum, G. Yu, and X. Fu, "A comparative analysis of productivity performance of the world's major airports: summary report of the ATRS global airport benchmarking research report-2002," Journal of Air Transport Management, vol. 9, no. 5, pp. 285-297, 2003.

[29] L. C. Lin and C. H. Hong, "Operational performance evaluation of international major airports: An application of data envelopment analysis," Journal of Air Transport Management, vol. 12, no. 6, pp. 342-351, 2006.

[30] Y.-H. Ahn and H. Min, "Evaluating the multi-period operating efficiency of international airports using data envelopment analysis and the Malmquist productivity index," Journal of Air Transport Management, vol. 39, no. 1, pp. 12-22, 2014. 
[31] A. Charnes, W. W. Cooper, and E. Rhodes, "Measuring the efficiency of decision making units," European Journal of Operational Research, vol. 2, no. 6, pp. 429-444, 1978.

[32] R. D. Banker, A. Charnes, and W. W. Cooper, "Some models for estimating technical and scale inefficiencies in data envelopment analysis," Management Science, vol. 30, no. 9, pp. 1078-1092, 1984.

[33] C. P. Barros and M. Athanassiou, "Efficiency in European Seaports with DEA: Evidence from Greece and Portugal," Maritime Economics \& Logistics, vol. 6, no. 2, pp. 122-140, 2004.

[34] D. Gillen and A. Lall, "Developing measures of airport productivity and performance: an application of data envelopment analysis," Transportation Research Part E: Logistics and Transportation Review, vol. 33, no. 4, pp. 261-273, 1997.

[35] E. Fernandes and R. R. Pacheco, "Efficient use of airport capacity," Transportation Research Part A: Policy and Practice, vol. 36, no. 3, pp. 225-238, 2002.

[36] T. D'Alfonso, C. Daraio, and A. Nastasi, "Competition and efficiency in the Italian airport system: New insights from a conditional nonparametric frontier analysis," Transportation Research Part E: Logistics and Transportation Review, vol. 80, pp. 20-38, 2015.

[37] C. Lo Storto, "The analysis of the cost-revenue production cycle efficiency of the Italian airports: A NSBM DEA approach," Journal of Air Transport Management, vol. 72, no. 1, pp. 77-85, 2018.

[38] S. Lozano, E. Gutiérrez, and G. Moreno, "Network DEA approach to airports performance assessment considering undesirable outputs," Applied Mathematical Modelling, vol. 37, no. 4, pp. 1665-1676, 2013.

[39] M. M. Yu, "Assessment of airport performance using the SBM-NDEA model," Omega, vol. 38, no. 6, pp. 440-452, 2010.

[40] W. W. Cooper, B. Gu, and S. Li, "Comparisons and evaluations of alternative approaches to the treatment of congestion in DEA," European Journal of Operational Research, vol. 132, no. 1, pp. 62-74, 2001.

[41] W.-K. Wang, W.-M. Lu, and C.-J. Tsai, "The relationship between airline performance and corporate governance amongst US listed companies," Journal of Air Transport Management, vol. 17, no. 2, pp. 148-152, 2011.

[42] D. W. Caves, L. R. Christensen, and W. E. Diewert, "The economic theory of index numbers and the measurement of input, output, and productivity," Econometrica, vol. 50, no. 6, pp. 1393-1414, 1982.

[43] S. Serebrisky and E. Desli, "Productivity growth, technical Progress, and efficiency change in industrialized countries: comment," The American Economic Review, vol. 87, no. 5, pp. 1033-1039, 1997.

[44] A. O. Hirschman, National Power and the Structure of Foreign Trade, University of California Press, Berkeley, CA, USA, 1945.

[45] A. O. Hirschman, "The Paternity of an index," American Economic Review, vol. 54, no. 1, pp. 761-762, 1964.

[46] O. Herfindahl, Concentration in the U.S. Steel Industry, Dissertion, Columbia University, New York, NY, USA, 1950.

[47] S. Rhoades, "The Herfindahl-Hirschman index," Federal Reserve Bulletin, 1993.

[48] G. Sugiyanto, P. Bekti, S. A. Wibowo, and M. Y. Santi, "Hub and spoke airport networks in Indonesia based on HerfindahlHirschmann index (HHI)," Journal of Engineering and Applied Sciences, vol. 11, no. 1, pp. 1804-1810, 2016.

[49] P. N. Nguyen, S. H. Woo, A. Beresford, and S. Pettit, "Competition, market concentration, and relative efficiency of major container ports in Southeast Asia," Journal of Transport Geography, vol. 83, pp. 1-10, Article ID 102653, 2020. 